\title{
Genetic Variation in Mexican Jatropha curcas L. Estimated with Seed Oil Fatty Acids
}

\author{
I. Ovando-Medina ${ }^{1,4 *}$, FJ. Espinosa-García ${ }^{2}$, J. Núñez-Farfán ${ }^{3}$ and M. Salvador-Figueroa ${ }^{4}$ \\ ${ }^{1}$ Posgrado en Ciencias Biológicas. Universidad Nacional Autónoma de México (Ciudad Universitaria, Distrito Federal, MEXICO) \\ ${ }^{2}$ Centro de Investigación en Ecosistemas. Universidad Nacional Autónoma de México (Morelia, Michoacán, MEXICO) \\ ${ }^{3}$ Instituto de Ecología. Universidad Nacional Autónoma de México (Ciudad Universitaria, Distrito Federal, MEXICO) \\ ${ }^{4}$ Centro de Biociencias. Universidad Autónoma de Chiapas (Tapachula, Chiapas, MEXICO)
}

\begin{abstract}
The genetic diversity of Mesoamerican populations of the biofuel plant Jatropha curcas, using the fatty acids of the seeds as chemical markers was studied. The oil content of the whole seed in 135 accessions from 38 sites varied between $\mathbf{8 . 0 2 0} \%$ and $54.28 \%$. The prevalent fatty acids were oleic acid (18:1) and linoleic acid (18:2), and the proportion of unsaturated fatty acids varied between $74.5 \%$ and $83.7 \%$. A study with cloned plants grown in common garden showed that both the content of oil as well as the proportion of fatty acids are highly inheritable, therefore these chemical markers are valid for estimating the genetic diversity of the species. An analysis of principal components showed that the fatty acids that contribute more to the variance are stearic, oleic, linoleic, methylpalmitic, gadoleic and ricinoleic. The populations were classified in ten groups when the data were analyzed for fatty acids by analysis of clusters, showing the elevated genetic variation in natural populations of this native species of Mesoamerica. A discriminant analysis separated the populations in accordance with their geographic origin, which was verified with a Mantel test. Using the Monmonier's algorithm two genetic barriers between the populations were identified. The results are discussed in light of their microevolutionary significance.
\end{abstract}

Key words: seed oil, Jatropha, Mesoamerica, Mexico, genetic diversity

\section{INTRODUCTION}

Jatropha curcas L. is perhaps currently the plant of greatest importance for the extraction of oil for the fabrication of biodiesel. Various authors have mentioned the advantageous characteristics of this plant from the family Euphorbiaceae, in comparison with other oleaginous plants, highlighting particularly its adaptation to marginal environments $^{1-4)}$.

Although there is no consensus about the origin of this species, many researchers point to the Mesoamerican region (Mexico and Central America) as its center of origin ${ }^{5-7}$, while others mention South America ${ }^{8,9)}$; but there is no doubt that Mesoamerica is the center of diversification of the genus Jatropha $a^{10)}$ and that this region held the source material for establishment of present populations in Africa and Asia. Moreover, only in Mexico do domesticated genotypes exist of low or null toxicity ${ }^{11,12)}$.

In the last decade, the number of studies and publications on $J$. curcas have grown geometrically, driven by the growing interest of governmental agencies in many parts of the world, but above all in Southeast Asia, in the cultiva- tion of the plant. Notoriously, the majority of these reports used Asian accessions to study the agronomic performance, the genetic variation through molecular markers, and of course, the content and composition of the seed oil ${ }^{13-18)}$. To a lesser extent, accessions from South America ${ }^{19,20)}$ and from Africa ${ }^{21)}$ have been studied. When samples from the Mesoamerican region have been used, it has been only for comparison. On the other hand, little attention has been paid to the composition of fatty acids of the seeds as chemical markers for estimating the genetic diversity of this plant; instead, the studies have been focused on determining the proportion of saturated or unsaturated fatty acids due to their importance in the production of biodiesel, as foodstuff and for usage in industrial processes ${ }^{22-25)}$, with the exception of the work of Wang et $a l{ }^{26)}$, who studied some accessions of $J$. curcas introduced in China.

In the present study the content of oil in the seeds was investigated along with its composition of fatty acids in Mexican populations of $J$. curcas, with the purpose of estimating the level of chemical variation and relating this with its evolutionary meaning.

\footnotetext{
*Correspondence to: I. Ovando-Medina, Centro de Biociencias-Universidad Autónoma de Chiapas, Carretera a Puerto Madero Km 2.0, Tapachula, 30700, Chiapas, MEXICO

E-mail: isidro.ovando @ unach.mx

Accepted February 14, 2011 (received for review October 12, 2010)

Journal of Oleo Science ISSN 1345-8957 print / ISSN 1347-3352 online

http://www.jstage.jst.go.jp/browse/jos/
} 


\section{Ovando-Medina, F. Espinosa-García, J. Núñez-Farfán and M. Salvador-Figueroa}

\section{EXPERIMENTAL PROCEDURES}

\subsection{Sample collection}

Plants of $J$. curcas were studied in the Mesoamerican region, covering a total of 38 sites which were a priori grouped into 6 populations from areas in the south and southeast of Mexico, and in Guatemala (Table 1, Fig. 4). Each population was represented by at least five trees in the stage of seed production (rainy season, August-September of 2008), from which were collected close to $100 \mathrm{~g}$ of seed from each plant. Cuttings of $80 \mathrm{~cm}$ in length were also collected, which were rooted in a greenhouse and taken in as 135 accessions of the Bank of Jatropha in the Center for Biosciences at the Autonomous University of Chiapas (Tapachula, Chiapas, Mexico).

\subsection{Extraction of oil and preparation of FAMEs}

The seeds from each site were dried at room temperature for at least 30 days, until they possessed less than $2 \%$ moisture. The whole seeds (including seed coat, endosperm and embryo)were crushed in a mortar washed with hexane, homogenized, and sampled in triplicate $10 \mathrm{~g}$ of the resulting paste for determining the content of oil. The method utilized was Soxhlet 920.39 of the Association of Official Analytical Chemists $^{27)}$. To prepare Fatty Acid Methyl Esters (FAMEs), the method of Ichihara et $a l .{ }^{28)}$ was followed -with modifications. In a screw-top test tube previously washed with hexane and dried for $2 \mathrm{~h}$ at $300^{\circ} \mathrm{C}, 2 \mathrm{~mL}$ of n-hexane were introduced and $40 \mathrm{mg}$ of crude oil were added. The sealed test tubes were brought to $40^{\circ} \mathrm{C}$ in a bath of water for $1 \mathrm{~min}$ and $200 \mu \mathrm{L}$ of a solution of methanolic NaOH 2.0 M were added. These were agitated in vortex for $2 \mathrm{~min}$, returned to heat for $1 \mathrm{~min}$ and centrifuged at $5000 \mathrm{rpm}$ for 10 minutes. The upper hexane phase was separated containing the prepared FAMEs.

\subsection{Determination of the composition of fatty acids by gas chromatography}

The fatty acids were analyzed by gas chromatography/ mass spectrometry (Chromatograph Agilent 6890), injecting $0.5 \overline{\mathrm{O}} \mathrm{L}$ of the FAMEs from each accession into a column of intermediate polarity (Equity-1, Supelco 28046-U, $30 \mathrm{~m} \times 250 \mu \mathrm{m} \times 0.30 \mu \mathrm{m})$, with the following program of temperatures: $100^{\circ} \mathrm{C}, 25^{\circ} \mathrm{C} \mathrm{min}^{-1}$ to $200^{\circ} \mathrm{C}, 2.5^{\circ} \mathrm{C} \mathrm{min}^{-1}$ to $230^{\circ} \mathrm{C}$ per one minute, $10^{\circ} \mathrm{C} \mathrm{min}^{-1}$ to $250^{\circ} \mathrm{C}$ ). The chromatograph was operated using helium as carrier gas $(7.48$ psi). The injector was programmed in mode Split 60:1 to a temperature of $280^{\circ} \mathrm{C}$. A selective mass detector was used (Agilent 5973 Network) operated at a voltage of ionization of $70 \mathrm{eV}$, with a temperature interface of $280^{\circ} \mathrm{C}$, Scan mode and mass rank of 50 to $550 \mathrm{~m} / \mathrm{z}$. The compounds from each one of the samples were identified by comparing their mass spectra with those of Library of the National Institute of Standards and Technology (NIST98). The concentration of each compound was obtained comparing its abundance with that of the internal standard, methyl ester of nonadecanoic acid, and considering the total concentration of the fatty acids as $100 \%$. The relative proportions for each compound were reported in percentage.

\subsection{Study in common garden with cloned plants}

To study if the composition and proportion of fatty acids in the oil of $J$. curcas of Mesoamerica are fixed characters, 15 accessions clonally reproduced and situated in the Bank of Jatropha were evaluated under similar conditions (cultivated during a year in rain-fed andosol approximately 2500 mm raifall in the 2008-2009 cycle-, average annual temperature of $30^{\circ} \mathrm{C}$, without agronomic management). The plants initiated their flowering in May 2009 and the production of seeds in July, so that $100 \mathrm{~g}$ of seeds were collected from three clones per accession during August-September of 2009. The preparation of samples, extraction of oil, obtaining of FAMEs and chromatographic analysis were made under the conditions described above.

\subsection{Statistical analysis}

The data for oil content were processed through an analysis of variance. The proportion of saturated/unsaturated fatty acids was compared between sites, and an exploration was made for possible Pearson correlations ( $\alpha$ 0.05) between the altitude and latitude of the collection sites and the content and composition of the oils. For this, the software XLStatC 2010.3.03 (AddinSoft, USA) was utilized.

With the data derived from plants cloned and grown in common garden the broad sense heritability was studied for the fatty acids and the oil content, utilizing the online software PBStatC $1.02^{29)}$. With the data of proportions for fatty acids in seeds collected from the sites, analyses of principal components, discriminant and clusters (utilizing Euclidean distances and grouping by average linkage)were made. These analyses were done with XLStatC 2010.3.03.

Isolation by distance was tested through the correlation of matrices of Euclidean and geographic distances using the Mantel test with 10000 permutations. The geographic distances were obtained by means of latitude/longitude of the sites, using GenAlEx 6.0 $0^{30)}$. To test the existence of possible genetic barriers between populations the software Barrier 2.2 ${ }^{31)}$ was utilized, correlating a Fisher distance matrix, as generated in a discriminant analysis, with a matrix of average decimal geographic distances of each population.

\section{RESULTS}

\subsection{Content and composition of the seed oil}

The quantity of oil in the seed of Mesoamerican J. curcas by individual varied between 8.02 and $54.28 \%$, while the variation per site was between 12.09 and $44.27 \%$ (Ta- 
Table 1 Location data, oil content seed and proportion of unsaturated fatty acids in accessions of Jatropha curcas $\mathrm{L}$. from 38 sites in the Mesoamerican region.

\begin{tabular}{|c|c|c|c|c|c|c|}
\hline Population & Site & $\begin{array}{l}\text { Number of } \\
\text { accessions }\end{array}$ & Latitude / Longitude & $\begin{array}{l}\text { Altitude } \\
\text { (masl) }\end{array}$ & $\begin{array}{c}\text { Seed Oil } \\
\text { Content }(\%)\end{array}$ & $\begin{array}{c}\text { Unsaturated } \\
\text { Fatty Acids (\%) }\end{array}$ \\
\hline Coast of Chiapas & $\mathrm{ACA}$ & 5 & $15.1040 /-92.3511$ & 51.0 & 37.22 & 78.96 \\
\hline Coast of Chiapas & CAC & 2 & $14.5901 /-92.5941$ & 472.0 & 25.13 & 82.29 \\
\hline Coast of Chiapas & HUX & 5 & $15.0402 /-92.2922$ & 23.0 & 37.11 & 74.52 \\
\hline Coast of Chiapas & MAP & 5 & $15.2540 /-92.5384$ & 34.8 & 39.88 & 79.62 \\
\hline Coast of Chiapas & $\mathrm{PC}$ & 5 & $14.4371 /-92.2578$ & 5.4 & 33.59 & 81.05 \\
\hline Coast of Chiapas & $\mathrm{SCH}$ & 5 & $14.3957 /-92.1032$ & 24.3 & 34.65 & 78.31 \\
\hline Coast of Chiapas & TAP & 5 & $14.5453 /-92.1925$ & 74.4 & 32.23 & 78.91 \\
\hline Coast of Chiapas & TON & 1 & $16.0343 /-93.5078$ & 12.0 & 39.29 & 83.42 \\
\hline Coast of Chiapas & ARR & 5 & $16.1141 /-93.6359$ & 53.0 & 40.25 & 82.50 \\
\hline Coast of Chiapas & PIJ & 5 & $15.5552 /-92.5956$ & 79.0 & 33.80 & 79.99 \\
\hline Center of Chiapas & BERR & 4 & $16.4760 /-93.1625$ & 895.8 & 35.76 & 82.85 \\
\hline Center of Chiapas & $\mathrm{CIN}$ & 4 & $16.4113 /-93.4265$ & 574.8 & 17.51 & 80.44 \\
\hline Center of Chiapas & JIQ & 4 & $16.4004 /-93.3922$ & 533.3 & 40.69 & 79.69 \\
\hline Center of Chiapas & $\mathrm{OCZ}$ & 3 & $16.4623 /-93.2372$ & 803.3 & 19.99 & 82.10 \\
\hline Center of Chiapas & TYL & 1 & $16.2269 /-93.4918$ & 689.0 & 14.18 & 77.84 \\
\hline Center of Chiapas & TUX & 1 & $16.4233 /-93.0670$ & 894.0 & 12.20 & 78.72 \\
\hline Center of Chiapas & CCR & 4 & $16.0664 /-92.4104$ & 537.5 & 12.09 & 83.02 \\
\hline Center of Chiapas & PUJ & 3 & $16.1569 /-92.1747$ & 511.0 & 37.71 & 78.22 \\
\hline Center of Chiapas & RV & 3 & $16.0993 /-93.0453$ & 560.7 & 43.12 & 81.02 \\
\hline Center of Chiapas & VCR & 1 & $16.1831 /-93.0454$ & 830.0 & 18.90 & 77.69 \\
\hline Center of Chiapas & $\mathrm{VCO}$ & 1 & $16.1169 /-93.1563$ & 579.0 & 26.21 & 77.72 \\
\hline Center of Chiapas & VIF & 1 & $16.1482 /-93.1578$ & 564.0 & 31.16 & 78.43 \\
\hline Center of Chiapas & VLR & 1 & $16.1924 /-92.2057$ & 1304.0 & 21.14 & 83.78 \\
\hline Center of Chiapas & $\mathrm{CHIC}$ & 5 & $15.4465 /-92.1672$ & 587.8 & 14.52 & 83.44 \\
\hline Center of Chiapas & $\mathrm{CDCU}$ & 5 & $15.4050 /-92.0012$ & 700.8 & 26.76 & 82.71 \\
\hline Center of Chiapas & $\mathrm{COM}$ & 5 & $15.3918 /-92.0801$ & 677.4 & 27.12 & 83.20 \\
\hline Center of Chiapas & LACO & 2 & $15.5029 /-91.5422$ & 635.0 & 44.27 & 79.25 \\
\hline Center of Chiapas & LAGOS & 5 & $15.5034 /-91.5437$ & 631.0 & 30.04 & 80.26 \\
\hline Center of Chiapas & RIZ & 3 & $15.5794 /-92.2884$ & 561.0 & 27.90 & 81.77 \\
\hline Center of Chiapas & IXT & 4 & $16.4722 /-92.5463$ & 813.0 & 32.17 & 77.31 \\
\hline Guatemala & GUA & 5 & $14.3627 /-90.2908$ & 1245.6 & 31.88 & 80.97 \\
\hline Oaxaca & $\mathrm{ECO}$ & 4 & $15.4339 /-96.3386$ & 61.8 & 28.41 & 80.44 \\
\hline Oaxaca & ZIM & 1 & $15.5056 /-96.0015$ & 66.0 & 22.39 & 79.55 \\
\hline Oaxaca & PA & 5 & $16.1125 /-97.4476$ & 37.8 & 32.00 & 80.71 \\
\hline Oaxaca & PIN & 3 & $16.1931 /-97.5355$ & 263.7 & 25.24 & 81.96 \\
\hline Guerrero & $\mathrm{COP}$ & 4 & $16.3747 /-99.0074$ & 8.5 & 24.77 & 79.46 \\
\hline Guerrero & ACAP & 5 & $16.4996 /-99.4688$ & 19.2 & 24.73 & 80.49 \\
\hline Michoacán & APA & 5 & $19.0424 /-102.2210$ & 312.4 & 29.33 & 77.97 \\
\hline
\end{tabular}


ble 1), which was significant $(\mathrm{F}=8.205, P<\mathrm{F} 0.0001)$. It was found that the oil content is negatively correlated with the altitude at which the plants were growing (Fig. 1a). There was no significant correlation with the latitudes of collection sites.

Eleven transesterified fatty acids were found: Decanoic Acid (Capric Acid 10:0), Tetradecanoic Acid (Myristic Acid 14:0), Hexadecanoic acid (Palmitic Acid 16:0), 9-Hexadecenoic Acid (Palmitoleic Acid 16:1), 14-Methyl Hexadecanoic Acid (Methyl Palmitic Acid 17:0), Octadecanoic Acid
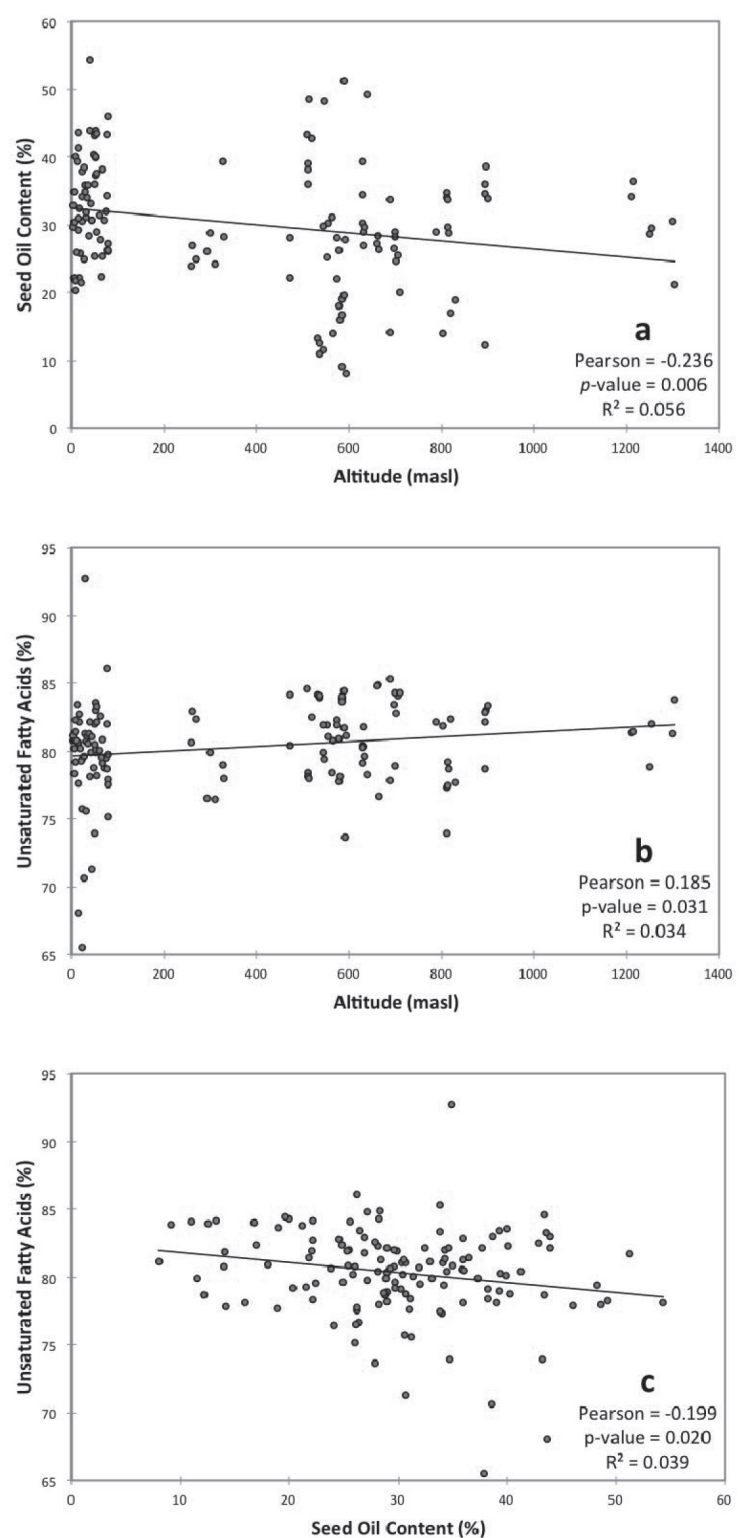

Fig. 1 Significant correlations between parameters of the seed oil of Mesoamerican Jatropha curcas; a) Seed oil content vs. altitude, b) Unsaturated fatty acids vs altitude, c) Unsaturated fatty acid vs seed oil content.
(Stearic Acid 18:0), 9-Octadecenoic Acid (Oleic Acid 18:1), 7-Hydroxy,9-Octadecenoic Acid (Ricinoleic Acid 18:1), 9,12-Octadecadienoic Acid, (Linoleic acid 18:2), Eicosanoic Acid (Arachidic Acid 20:0), Eicosenoic Acid (Gadoleic Acid 20:1). In addition, several accessions showed 3-Octyl,Oxirane-Octanoic Acid (16:0) and / or Decanedioic Acid (11:0, Sebacic Acid, Dicarboxylic), which could be intermediary products of synthesis or degradation of other fatty acids.

The most abundant fatty acids were oleic(average $38.7 \%$ ), linoleic (average $40.7 \%$ ), palmitic (average $12.8 \%)$ and stearic (6.1\% in average). The proportion of unsaturated fatty acids varied between 59.14 and $86.76 \%$, considering the individuals, while the variation per site was between 74.5 and $83.8 \%$, which was significant $(\mathrm{F}=1.633$, $\mathrm{P}=0.029$; Table 1). The proportion of unsaturated fatty acids is weakly but positively correlated with the altitude (Fig. 1b). There was no significant correlation with the latitude of the sites. The oil content and the unsaturated fatty acid proportion are negatively correlated (Fig. 1c).

\subsection{Most informative and heritability of characters}

The principal components analysis (PCA) showed that the variables stearic, oleic and linoleic acids contributed mainly to the first principal component; consequently, those variables can be considered the most informative of the variation detected (Table 2). The study with cloned plants showed that almost all fatty acids had very high broad sense heritabilities (around 90\%), except for the case of palmitoleic acid, of which it was not possible to estimate the heritability, since statistically significant differences between genotypes were not detected; whereas the

Table 2 Contributions of the variables (\%) to the first two principal components (F1 and F2).

\begin{tabular}{lcr}
\hline \multicolumn{1}{c}{ Variable } & F1 & \multicolumn{1}{c}{ F2 } \\
\hline Myristic Acid (14:0) & 0.033 & 0.463 \\
Palmitic Acid (16:0) & 6.767 & 10.802 \\
Palmitoleic Acid (16:1) & 0.504 & 17.875 \\
Methyl-Palmitic Acid (17:0) & 1.288 & 17.468 \\
Stearic Acid (18:0) & 18.666 & 0.493 \\
Oleic Acid (18:1) & 24.353 & 6.621 \\
Linoleic Acid (18:2) & 31.988 & 3.672 \\
Arachidic Acid (20:0) & 4.827 & 0.452 \\
Gadoleic Acid (20:1) & 2.690 & 23.049 \\
Capric Acid (10:0) & 0.874 & 0.595 \\
Ricinoleic Acid (18:1) & 1.777 & 18.332 \\
Seed Oil Content (\%) & 6.234 & 0.176 \\
\hline Bold values correspond, for
\end{tabular}

Bold values correspond, for each variable, to the factor for which the squared cosine is the largest. 
Table 3 Estimation of the broad sense heritability of the characters studied.

\begin{tabular}{lrrr}
\hline \multicolumn{1}{c}{ Variable } & \multicolumn{1}{c}{$\mathrm{V}_{\mathrm{G}}$} & \multicolumn{1}{c}{$\mathrm{V}_{\mathrm{P}}$} & \multicolumn{1}{c}{$\mathrm{h}_{\text {bs }}^{2}(\%)$} \\
\hline MYRISTIC & 0.0056 & 0.0063 & 89.23 \\
PALMITIC & 29.8427 & 30.4945 & 97.86 \\
PALMITOLEIC & 0.0000 & 0.5984 & 0.00 \\
MPALMITIC & 0.0028 & 0.0031 & 92.08 \\
STEARIC & 9.7004 & 10.1895 & 95.20 \\
OLEIC & 24.0714 & 25.2182 & 95.45 \\
LINOLEIC & 36.0180 & 37.2547 & 96.68 \\
ARACHIDIC & 0.0509 & 0.0515 & 98.82 \\
GADOLEIC & 0.0032 & 0.0037 & 86.48 \\
RICINOLEIC & 0.0089 & 0.0215 & 41.35 \\
OILCONTENTS & 17.9423 & 25.5240 & 70.30 \\
\hline
\end{tabular}

$\mathrm{V}_{\mathrm{G}}$ : Genotypic variation; VP: Phenotypic variation;

$\mathrm{h}_{\text {bs }}^{2}$ : broad sense heritability, in percentage.

oil content had heritability of $70 \%$ (Table 3 ).

\subsection{Description of the variation}

Having confirmed the high heritability of fatty acids of the seed, we described the genetic variation using these characters as chemical markers. The analysis of ascending hierarchical classification grouped the 135 accessions into 10 groups, as shown in the dendrogram of Fig. 2, where the dotted line indicates the limit for the formation of groups. In general, it was observed that accessions are grouped according to their geographical origin, but some that belong to a same town or locality are in a different group.

It is noteworthy that the groups I, II and III with one, one and four accessions of the Coast of Chiapas, respectively, are clearly separated from the other accessions, including those of the rest of the mentioned population, i.e. they were outliers (Fig. 2). Groups IV to VIII contained accessions from the Center of Chiapas and populations of Guatemala, Oaxaca, Guerrero and 3 accessions of Michoacán, along with some accessions from the Coast of Chiapas. Groups IX and X contained almost exclusively accessions from the Coast of Chiapas, except ZIM1 (Oaxaca) and APA2 and APA5 (Michoacán).

The genetic variation encountered can be considered high given that the line forming groups stood at a Euclidean distance of 7.5, while the maximum distance between groups was 33. In addition, the variation within classes accounted for only $10.7 \%$, while the variation among classes was $89.3 \%$.

Discriminant analysis, it showed that the first two factors explain $89 \%$ of the variation and separated the accessions into three major groups in the bidimensional geometric space: the accessions of Michoacán, the Coast of Chiapas and Center of Chiapas; accessions of the other populations were mixed with those of the last two populations (Fig. 3a). To confirm the trends in spatial location, the centroids were plotted for each population (Fig. 3b), confirming that the population of Michoacán is isolated and that those of Chiapas are clearly far apart. The centroids of the populations of Guatemala and Guerrero overlap the Center of Chiapas. The Oaxacan population is related to that of Guerrero.

\subsection{Isolation of populations}

To evaluate the apparent ranking of accessions according to their origin, a Mantel test of association was performed, with significant results $((\mathrm{r}(\mathrm{AB})=-0.082) ; \mathrm{P}<$ $0.0001)$ ), which indicates that there was a correlation between genetic distance (Euclidean) and geographic distance in kilometers. Isolation was also shown by the existence of genetic barriers detected with Barrier vers. 2.2. The major barrier (a) separates the population of Central Chiapas of the rest of the populations, and the second barrier (b) isolates the population of Michoacán (Fig. 4).

\section{DISCUSSION}

The storage of oils in seeds is a generalized feature in higher plants, which serve as a source of energy for the embryo during the heterotrophic stage ${ }^{32)}$. This stage is crucial in the success or failure of the embryo to germinate, emerge and establish itself as a new plant ${ }^{33)}$, and therefore, the content of the endosperm, at least in part, determines reproductive success or "fitness" of the plant. As a result, the total content and composition of seed oil should be 


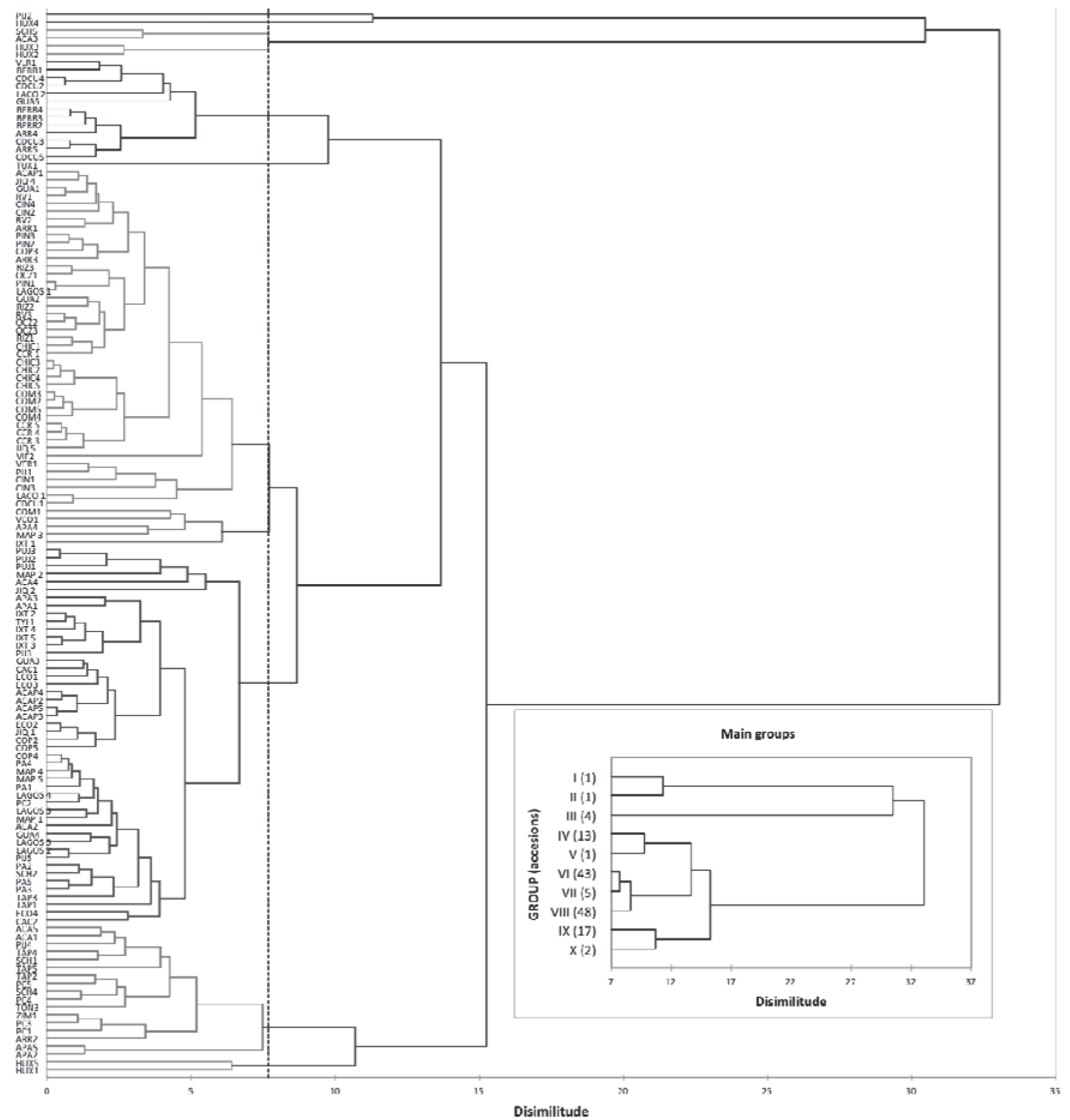

Fig. 2 Dendrogram of Euclidean distances for 135 accesiones de Jatropha curcas L. in the Mesoamerican region based on the proportion of 11 fatty acids in the seed. The box shows the ten groups, which were formed, and the number of accessions in each of them.

considered characters subject to natural selection. The present study, in a microevolutionary and not phylogenetic context, showed that the variation in oil content and fatty acid composition of the seed in populations of J. curcas in Mesoamerica is very high (Table 1) and that the chemical markers used are highly heritable (Table 3).

\subsection{Pattern of total oil content}

The quantity of oil determined by sites (between 12 and $44 \%$ of the mass of the whole seed) is consistent with pre- 
a
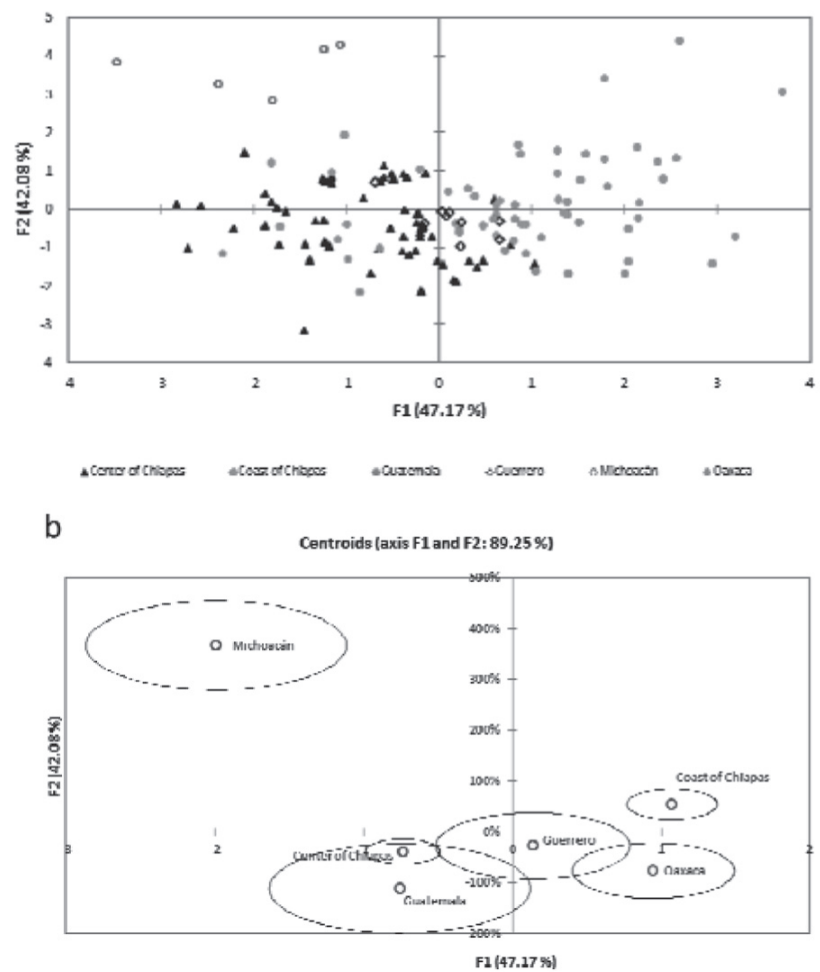

Fig. 3 Discriminant analysis of 135 accessions of Jatropha curcas L. from six Mesoamerican populations, based on the proportion of fatty acids in the seed; a) distribution in the bidimensional geometric space based in factors 1 and 2, b) distribution based on the centroids.

vious reports for this species, either cultivated in Asia or Africa ${ }^{5,34)}$ or collected in the Mesoamerican region ${ }^{11,12)}$. Similarly, the fact that there is a pattern of negative correlation with altitude confirm the findings of Pant et al ${ }^{35)}$ who determined the variation in yield and oil content of Indian accessions of $J$. curcas in two soil conditions and three altitudinal ranges, finding that there is a higher content of oil when the plant is found in non-arable soils and low elevation.

It has been documented that there is considerable variation in oil content of this species that can be generated by genetic and environmental factors, including rainfall and soil fertility ${ }^{36,37)}$. Heller ${ }^{5)}$ reported that variability in this characteristic might be influenced by the origin of the accessions studied and genotype-environment interactions. Contrary to this, Kaushik et al ${ }^{38)}$ reported that the oil content of twenty-four accessions of Indian $J$. curcas had a broad sense heritability of $99 \%$, implying a limited influence of the environment. However, they also reported a variation of only $10 \%$ among accessions and very low coefficients of phenotypic and genotypic variation, which con-

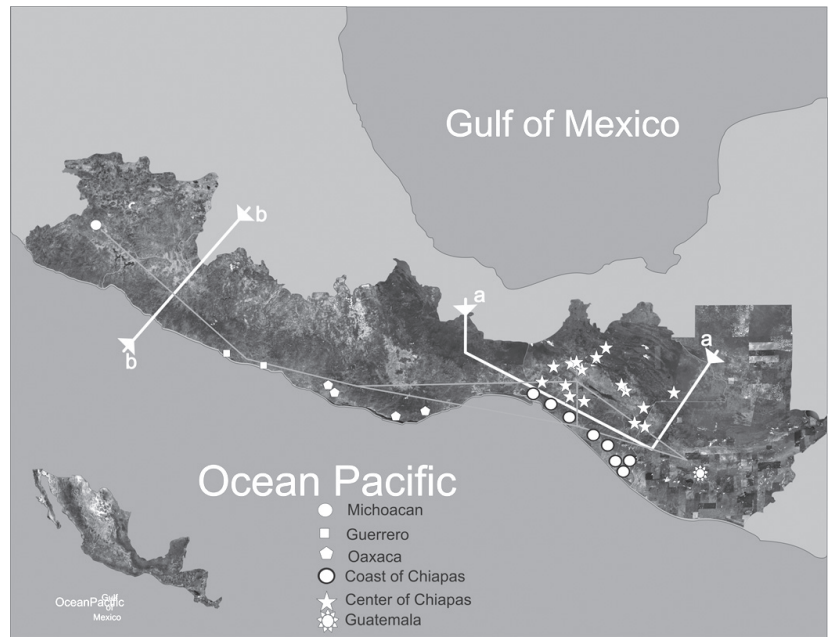

Fig. 4 Map showing the sites of collection of Jatropha curcas evaluated in their composition of oil from Southern Mexico and from Guatemala, and the two main genetic barriers (lines "a" and " $b$ " in yellow) found by the algorithm of Monmonier (Barrier vers. 2.2), as based on Fisher distances of fatty acid composition of the seed. Map kindly prepared by Francisco Javier Pérez Racancoj.

firms the narrow genetic basis of $J$. curcas in Asia. In the same way, Gohil and Pandya ${ }^{39)}$ reported $89.7 \%$ of broad sense heritability for this character.

Unlike the explanation of that phenomenon for Asian accessions, where $J$. curcas was introduced a few centuries ago and where the variation might be due to strong environmental effects by having a narrow genetic base ${ }^{40)}$, in Mesoamerican populations the reason could be the selection of genotypes adapted to adverse conditions (higher temperature) with increased production of energy substances for the embryo during germination. This increases seedling vigor and thus, the fitness of the species.

It is noteworthy that the oil content is a characteristic that had a high heritability ( $70 \%$ ), while it had a high coefficient of genotypic variation and $32 \%$ of variation among accessions (Tables 1 and 3 ), which shows that populations in Mesoamerica, where most likely $J$. curcas is a native of, are more variable than in other parts of the world.

Although there have been determinations of the oil content in higher plants for a long time, perhaps the first study to look for relationships between ecological parameters and accumulation of oil was that of Levin ${ }^{41)}$, who studied the relationship between oil content and the habit and habitat of over a thousand species of angiosperms, finding that the oil content, evolutionarily, has increased with the development of woody stems and shade tolerance, and there is no relation to the latitudinal origin. In the case of the tropical semi-domesticated plant $J$. curcas, in this study there was no significant correlation with latitude of 


\section{Ovando-Medina, F. Espinosa-García, J. Núñez-Farfán and M. Salvador-Figueroa}

collection sites. In a thorough review, no reports were found which examine this relationship, possibly conforming to that postulated by Levin. The high oil content is also consistent with the hypothesis of Levin because J. curcas can be considered a woody tree shrub. To test the hypothesis of variation according to the habits of growth, it would be of great scientific interest to know the correlation between the accumulation of seed oil and the degree of stem lignification of the 175 species of genus Jatropha.

\subsection{Pattern in the fatty acid composition}

Except for ricinoleic acid, which is characteristic of Ricinus communis L., all other fatty acids have been reported for J. curcas; although this fatty acid has been reported recently in the species J. gossypifolia and other Euphorbiaceae $^{42)}$. Either way, it was only found in seven of the 135 accessions studied and its heritability was low (Table 3); however, the PCA revealed that it is a relatively informative variable by having the highest percentage of variability in the second principal component (Table 2).

The fatty acid profile is consistent with that reported in other studies, which report the same four main fatty $\operatorname{acids}^{5,11,12,43,44)}$. Behenic (22:0) and linolenic (18:3) fatty acids, which have been reported for J. curcas $^{45)}$ were not found in the evaluated accessions. The proportion of unsaturated fatty acids is an important variable in the biodiesel manufacturing, since quality standards indicate it must be minimized ${ }^{46)}$. Interestingly, this study found that oil content and the proportion of unsaturated fatty acids are negatively correlated, which, if confirmed in a larger study of genetic association with outstanding genotypes, will permit genetic improvement for increased oil yield while decreasing unsaturated fatty acids.

To date great progress has been made in molecular understanding of the origin of the fatty acids in seeds and their diversification mechanisms ${ }^{47,48)}$. However, it is surprising how little attention has been given to the selection factors that drive the evolution of the fatty acid composition of seeds. In this regard, Linder ${ }^{49)}$ suggested that the temperature of germination is an important selective agent that causes the seed oils of plants native to high latitudes (or altitudes) to have a higher proportion of unsaturated fatty acids that plants in lower latitudes/altitudes. The explanation is that in cooler environments (high latitudes and altitudes) the catabolism of unsaturated fatty acids is more feasible compared to saturated, thus the seeds with more unsaturated fatty acids germinate and grow faster at lower temperatures, increasing their fitness, even at the expense of having less total energy available. On the other hand, in warm environments, such as the tropical, seeds with more saturated fatty acids are selectively favored because they have more energy and they do not need to germinate quickly, since the conditions in the tropics are more or less stable throughout the year.
However, although the proportion of unsaturated fatty acids was positively correlated with the altitude of the sites, the fatty acid composition of J. curcas seems to be in disagreement with the hypothesis described, because, being a tropical species, selection has favored a greater proportion of unsaturated fatty acids.

The same author mentions that the lack of association between germination temperature and the proportion of unsaturated fatty acids in one species could be due to the lack of genetic variation in oil composition, which, as described in this paper, is not the case of $J$. curcas.

Based on the foregoing, it is hypothesized that, in the case of J. curcas, soil moisture has exerted selection pressure to select a higher proportion of unsaturated fatty acids. It is well documented that this species is tolerant to drought, although adapting to different environments, from humid to semi-arid; however, the plant is susceptible to flooding, for example, according to Dehgan \& Schutzman ${ }^{50)}$, $J$. curcas is found in South America in seasonally dry tropical areas, but is completely absent in the always wet Amazon region. In the Mesoamerican tropical region, the onset of flowering and seed production coincides with the onset of the rainy season, so seeds, which do not exhibit dormancy, should germinate quickly, usually within five days (for which they require higher proportion of unsaturated fatty acids) and establish themselves as seedlings before soil moisture levels increase to waterlogging.

\subsection{Patterns of diversity of Mexican J. curcas}

The analysis of clusters showed that genetic diversity of Mesoamerican $J$. curcas is high, as shown by the 7.5 units of Euclidean distance that marked the line of formation of the 10 clusters (Fig. 2); unfortunately, there are no reports of similar works with which to compare the variation using fatty acids as markers. Except for the work of Wang et $a l .^{26)}$, who compared the oil content and fatty acid composition in samples of $J$. curcas collected from three regions of China and India, finding 12 fatty acids and reporting differences between accessions. They concluded that attention should be given to these chemical markers to introduce new Chinese germplasm and for the genetic improvement of the plant.

Discriminant analysis separated the populations more or less according to their geographical origin(Fig. 3); this was checked with the Mantel test, which indicated a correlation between chemical and geographical distance. In contrast to these results, Kaushik et al. ${ }^{38)}$ evaluated 24 accessions of $J$. curcas from India to establish the genetic variability, where the pattern of clustering in the Euclidean cluster analysis revealed that geographic diversity does not necessarily represent the genetic diversity.

In our study two genetic barriers could be identified (Fig. 4) that separated populations of the Center of Chiapas and Michoacán. Possible explanations are related to the exis- 
tence of the mountain chain "Sierra Madre del Sur" which functions as a geographic barrier; the population of Center of Chiapas is the only one that is to the North of this mountain chain. Other possible reason is the geographical remoteness of the population in Michoacán from the rest of the populations. Studies with molecular markers based on DNA may provide information about the rate of gene flow between populations and confirm or reject the existence of the genetic barriers mentioned in Mesoamerican J. curcas.

\section{CONCLUSION}

The results of the work showed that the variation in the oil content and eleven fatty acid was very high with heritabilities of about $90 \%$, which demonstrate that they are useful markers in estimating the genetic diversity of $J$. curcas. The populations of $J$. curcas from the Mesoamerican region represent valuable genetic resources for the future establishment of extensive plantations of this oil producing plant.

\section{ACKNOWLEDGMENTS}

To the Posgrado en Ciencias Biologicas of the Universidad Nacional Autonoma de Mexico, for the education given to the first author during his doctoral studies. To the Consejo Nacional de Ciencia y Tecnología of Mexico (CONACyT), for the scholarship given to the first author. To Yolanda García Rodríguez of CIEco-UNAM, for her assistance in the chromatographic analysis.

\section{References}

1) Berchmans, H. J.; Hirata, S. Biodiesel production from crude Jatropha curcas L. seed oil with a high content of free fatty acids. Biores. Technol. 99, 1716-1721 (2008).

2) Abou-Kheira, A.; Atta, N. Response of Jatropha curcas L. to water deficit: Yield, water use efficiency and oilseed characteristics. Biomass Bioenerg. 33, 1343-1350 (2009).

3) Maes, W.; Achten, W.; Reubens, B.; Raes, D.; Samson, R.; Muys, B. Plant-water relationships and growth strategies of Jatropha curcas L. seedlings under different levels of drought stress. J. Arid Environ. 73, 877-884(2009).

4) Ovando-Medina, I.; Espinosa-García, F.; Núñez-Farfán, J.; Salvador-Figueroa, M. Does Biodiesel from Jatropha curcas represent a sustainable alternative energy source? Sustainability 1, 1035-1041 (2009).

5) Heller, J. Physic nut Jatropha curcas L. promoting the conservation and use of underutilized and neglected crops $1.1^{\text {st }}$ ed. International Plant Genetic Resources Institute. Rome. pp. 13-35(1996).

6) Openshaw, K. A review of Jatropha curcas: an oil plant of unfulfilled promise. Biomass Bioenerg. 19, 1-15(2000).

7) Ranade, S. A.; Srivastava, A. P.; Rana, T. S.; Srivastava, J.; Tuli, R. Easy assessment of diversity in Jatropha curcas L. plants using two single-primer amplification reaction (SPAR) methods. Biomass Bioenerg. 32, 533-540 (2008).

8) Martin, G.; Mayeux, A. Réflexions sur les cultures oléagineuses énergétiques. II. -Le Pourghère (Jatropha curcas L.): un carburant possible. Oléagineux 39, 283-287 (1984).

9) Basha, S. D.; Sujatha, M. Genetic analysis of Jatropha species and interspecific hybrids of Jatropha curcas using nuclear and organelle specific markers. Euphytica 168, 197-214(2009).

10) Dehgan, B.; Webster, G. Morphology and infrageneric relationships of the genus Jatropha (Euphorbiaceae). Univ. Calif. Publ. Bot. 74, 1-73(1979).

11) Makkar, H. P. S.; Martínez-Herrera, J.; Becker, K. Variations in seed number per fruit, seed physical parameters and contents of oil, protein and phorbol esters in toxic and non-toxic genotypes of Jatropha curcas. J. Plant. Sci. 3, 260-265(2008).

12) Martínez-Herrera, J.; Martínez-Ayala, A. L.; Makkar, H.; Francis, G.; Becker, K. Agroclimatic conditions, chemical and nutritional characterization of different provenances of Jatropha curcas L. from Mexico. Eur. J. Sci. Res. 39, 396-407(2010).

13) Sujatha, M.; Makkar, H. P. S.; Becker, K. Shoot bud proliferation from axillary nodes and leaf sections of non-toxic Jatropha curcas L. Plant Growth Regul. 47, 83-90 (2005).

14) Basha, S.; Sujatha, M. Inter and intra-population variability of Jatropha curcas (L.) characterized by RAPD and ISSR markers and development of population-specific SCAR markers. Euphytica 156, 375-386 (2007).

15) Kumar, G. P.; Yadav, S. K.; Thawales, P. R.; Singh, S. K.; Juwarkar, A. A. Growth of Jatropha curcas on heavy metal contaminated soil amended with industrial wastes and Azotobacter-A greenhouse study. Biores. Technol. 99, 2078-2082 (2008).

16) Behera, S. K.; Srivastava, P.; Tripathi, R.; Singh, J. P.; Singh, N. Evaluation of plant performance of Jatropha curcas L. under different agro-practices for optimizing biomass-A case study. Biomass Bioenerg. 34, 30-41 (2010).

17) Pamidimarri, D. V. N.; Singh, S.; Mastan, S. G.; Patel, J.; Reddy, M. P. Molecular characterization and identification of markers for toxic and non-toxic varieties of Jatropha curcas L. using RAPD, AFLP and SSR mark- 


\section{Ovando-Medina, F. Espinosa-García, J. Núñez-Farfán and M. Salvador-Figueroa}

ers. Mol. Biol. Rep. 36, 1357-1364(2009).

18) Tatikonda, L.; Wani, S. P.; Kannan, S.; Beerelli, N.; Sreedevi, T. K.; Hoisington, D. A.; Devi, P.; Varshney, R. K. AFLP-based molecular characterization of an elite germplasm collection of Jatropha curcas L., a biofuel plant. Plant Sci. 176, 505-513(2009).

19) Hartmann-Neto, I.; Alencar, J.; Diniz, F.; Souza, V.; Araujo, E.; Lima, P. Seleção de primers para uso de ISSR naanalise de diversidade genética empinhãomanso (Jatropha curcas L.). in 2nd Brazilian Congress of Mamona, Sergipe, Brazil, Abstracts (2006).

20) Oliveira, A. S.; Silva-Mann, R.; Santos, M. F.; Gois, I. B.; Carvalho, S. V.; Boari, A. J.; Fraga, A. C.; Castro-Neto, P. Prospecção e caracterização de acessos de Jatrophasp. in 2nd Brazilian Congress of Mamona, Sergipe, Brazil, Abstracts (2006).

21) Popluechai, S.; Breviario, D.; Mulpuri, S.; Makkar, H. P. S.; Raorane, M.; Reddy, A. R.; Palchetti, E.; Gatehouse, A. M. R.; Syers, J. K.; O’ Donnell, A. G.; Kohli, A. Narrow genetic and apparent phenetic diversity in Jatropha curcas: initial success with generating low phorbol ester interspecific hybrids. Nat. Preced. http://hdl. handle.net/10101/npre. 2009.2782.1(2009).

22) Abedowale, K. O.; Adedire, C. O. Chemical composition and insecticidal properties of the underutilized Jatropha curcas seed oil. Afr. J. Biotechnol. 5, 901-906 (2006).

23) Martínez-Herrera, J.; Siddhuraju, G. F.; Dávila-Ortiz, G.; Becker, K. Chemical composition, toxic/antimetabolic constituents, and effects of different treatments on their levels, in four provenances of Jatropha curcas L. from Mexico. J. Food Chem. 96, 80-89 (2006).

24) Salimon, J.; Abdullah, R. Physicochemical properties of Malaysian Jatropha curcas seed oil. Sains Malaysiana 37, 379-382 (2008).

25) Akbar, E.; Yaakob, Z.; Kamarudin, S. K.; Ismail, M.; Salimon, J. Characteristic and composition of Jatropha curcas oil seed from Malaysia and its potential as biodiesel feedstock. Eur. J. Sci. Res. 29, 396-403 (2009).

26) Wang, Z. Y.; Lin, J. M.; Xu, Z. F. Oil contents and fatty acid composition in Jatropha curcas seeds collected from different regions. Nan fang yi ke da xue xue bao (J. South Med. Univ. ) 28, 1045-1046 (2008).

27) AOAC. Official methods of analysis. Method 920.39. $17^{\text {th }}$ ed. Association of Official Analytical Chemists. Washington (1997).

28) Ichihara, K.; Shibahara, A.; Yamamoto, K.; Nakayama, $\mathrm{T}$. An improved method for rapid analysis of the fatty acids of glycerolipids. Lipids 31, 535-539 (1996).

29) Bayuardi-Suwarno, W.; Sobir; Aswidinnoor, H.; Syukur, M. PBSTAT: A web- based statistical analysis software for participatory plant breeding. in 3rd Int Conf Math Stat (ICoMS-3), Indonesia, Abstracts. (2008)
30) Peakall, R.; Smouse, P. E. GENALEX 6: Genetic analysis in Excel. Population genetic software for teaching and research. Mol. Ecol. Notes 6, 288-295(2006).

31) Manni, F.; Guérard, E.; Heyer, E. Geographic patterns of (genetic, morphologic, linguistic) variation: how barriers can be detected by "Monmonier' s algorithm". Hum. Biol. 76, 173-190(2004).

32) Pujar, A.; Jaiswal, P.; Kellog, E. A.; Ilic, K.; Vincent, L.; Avraham, S.; Stevens, P.; Zapata, F.; Reiser, L.; Rhee, S. Y.; Sachs, M. M.; Schaeffer, M.; Stein, L.; Ware, D.; McCouch, S. Whole-plant growth stage ontology for angiosperms and its application in plant biology. Plant Physiol. 142, 414-428(2006).

33) Bewley, J. D.; Black, M. Seeds: physiology of development and germination. $2^{\text {nd }}$ ed. Plenum Press. New York. pp. 311-322 (1994).

34) Achten, W. M. J.; Mathijs, E.; Verchot, L.; Singh, V. P.; Aerts, R.; Muys, B. Jatropha biodiesel fueling sustainability? Biofuels Bioprod. Biorefin. 1, 283-291 (2007).

35) Pant, K. S.; Khosla, V.; Kumar, D.; Gairola, S. Seed oil content variation in Jatropha curcas Linn. in different altitudinal ranges and site conditions in H.P. India. Lyonia 11, 31-34(2006).

36) Escobar, J. C.; Lora, E. S.; Venturini, O. J.; Yáñez, E. E.; Castillo, E. F.; Almazán, O. Biofuels: Environment, technology and food security. Renew. Sust. Energ. Rev. 13, 1275-1287 (2008)

37) Mishra, D. K. Selection of candidate plus phenotypes of Jatropha curcas L. using method of paired comparisons. Biomass Bioenerg. 33, 542-545 (2008).

38) Kaushik, N.; Kumar, K.; Kumar, S.; Kaushik, N.Y.S.; Roy, S. Genetic variability and divergence studies in seed traits and oil content of Jatropha (Jatropha curcas L.) accessions. Biomass Bioenerg. 31, 497-502 (2007).

39) Gohil, R. H.; Pandya, J. B. Genetic diversity assessment in physic nut (Jatropha curcas L.). Int. J. Plant Prod. 2, 321-326 (2008).

40) Achten, W. M. J.; Nielsen, L. R.; Aerts, R.; Lengkeek, A. G.; Kjær, E. D.; Trabucco, A.; Hansen, J. K.; Maes, W. H.; Graudal, L.; Akinnifesi, F. K.; Muys, B. Towards domestication of Jatropha curcas. Future Sci. 1, 91-107(2010).

41) Levin, D. A. The oil content of seeds: an ecological perspective. Am. Nat. 108, 193-206 (1974).

42) Hosamani, K. M.; Katagi, K. S. Characterization and structure elucidation of 12-hydroxyoctadec-cis-9enoic acid in Jatropha gossypifolia and Hevea brasiliensis seed oils: a rich source of hydroxy fatty acid. Chem. Phys. Lipids 152, 9-12(2008).

43) Akintayo, E. T. Characteristics and composition of Parkia biglobbossa and Jatropha curcas oils and cakes. Biores. Technol. 92, 307-310(2004). 
44) Oyekunle, J. A. O.; Omode, A. A. Chemical composition and fatty acid profile of the lipid fractions of selected Nigerian indigenous oliseeds. Int. J. Food Prop. 11, 273-281 (2008).

45) Gubitz, G. M.; Mittelbach, M.; Trabi, M. Exploitation of the tropical seed plant Jatropha curcas L. Biores. Technol. 67, 73-82 (1999).

46) Conley, S. P. Biodiesel Quality: is All Biodiesel Created equal? Purdue Ext. BioEnerg. 338, 1-3(2006).

47) Barker, G.; Larson, T. R.; Graham, I. A.; Lynn, J. R.; King, G. J. Novel insights into seed fatty acid synthesis and modification pathways from genetic diversity and quantitative trait loci analysis of the Brassica C Genome. Plant Physiol. 144, 1827-1842 (2007).
48) Dyer, J. M.; Chapital, D. C.; Kuan, J. W.; Mullen, R. T.; Turner, C.; McKeon, T. A.; Pepperman, A. B. Molecular analysis of a bifunctional fatty acidconjugase/desaturase from Tung. Implications for theevolution of plant fatty acid diversity. Plant Physiol. 130, 2027-2038 (2002).

49) Linder, C. R. Adaptive evolution of seed oils in plants: accounting for the biogeographic distribution of saturated and unsaturated fatty acids in seed oils. Am. Nat. 156, 442-458(2000)

50) Dehgan, B.; Schutzman, B. Contributions toward a monograph of neotropical Jatropha: phenetic and phylogenetic analyses. Ann. Mo. Bot. Gard. 81, 349-367 (1994). 